\title{
Multiple Station Thermal Diffusivity Instrument
}

\author{
H. Wang*, R. B. Dinwiddie ${ }^{*}$ and P. S. Gaal ${ }^{+}$
}

"The submitted manuscript has been authored by a contractor of the U.S. government under contract NO. DE-AC05960R22464. Accordingly, the U.S. Government retains a nonexclusive, royalty-free license to publish or reproduce the published form of this contribution, or allow others to do so, for U.S. Government purposes."

\section{DISCLAIMER}

This report was prepared as an account of work sponsored by an agency of the United States Government. Neither the United States Government nor any agency thereof, nor any of their employees, makes any warranty, express or implied, or assumes any legal liability or responsibility for the accuracy, completeness, or usefulness of any information, apparatus, product, or process disclosed, or represents that its use would not infringe privately owned rights. Reference herein to any specific commercial product, process, or service by trade name, trademark, manufacturer, or otherwise does not necessarily constitute or imply its endorsement, recommendation, or favoring by the United States Government or any agency thereof. The views and opinions of authors expressed herein do not necessarily state or reflect those of the United States Government or any agency thereof. 


\section{ABSTRACT}

A multiple furnace laser flash thermal diffusivity system has been developed. The system is equipped with a movable Nd:Glass laser unit, two IR detectors and four furnaces for precise measurements of thermal diffusivity over the temperature range from $-150^{\circ} \mathrm{C}$ to $2500^{\circ} \mathrm{C}$. All furnaces can operate in vacuum and inert gas; the environmental effects furnace also supports oxidizing and reducing environments. To increase testing speed the graphite and aluminum furnaces are both equipped with six-sample carousels. Thermal diffusivity measurements of three standard reference materials show excellent results over the entire temperature range.

\section{INTRODUCTION}

Since its introduction in 1961[1], the laser flash technique has become a standard testing method for thermal diffusivity measurements of solids $[2,3]$. Traditionally, a single furnace is used for a certain temperature range and a few classes of materials.

\footnotetext{
"MS 6064, Bldg. 4515 Oak Ridge National Laboratory, Oak Ridge, TN 37830-6064

+Anter Corporation, 1700 Universal Road, Pittsburgh, PA 15235
} 
The rapid development of new materials often requires a laser flash system to cover a wider temperature range and to operate with different environments. This is particularly true for materials research and development. However, it is virtually impossible to find a single furnace type that can service the entire temperature domain of practical use, and to accommodate every material to be tested. Throughput in testing is a paramount factor even for fully automated systems.

The system which is the subject of this artucle is based on a traversing laser, multiple furnaces and two photovoltaic IR detectors. To suit a variety of testing requirements, the system is equipped with an ultra-high temperature graphite furnace $\left(500^{\circ} \mathrm{C}\right.$ to $2500^{\circ} \mathrm{C}$ ), a high temperature Kanthal Super ${ }^{\mathrm{TM}}$ furnace (RT to $1700^{\circ} \mathrm{C}$ ), a low temperature aluminum Monoblock ${ }^{\mathrm{TM}}$ furnace $\left(-150^{\circ} \mathrm{C}\right.$ to $\left.500^{\circ} \mathrm{C}\right)$, and a high speed quench furnace (RT to $1200^{\circ} \mathrm{C}$ ). It also provides the ability to add to and/or reconfigure an existing system as needs change. High throughput leads to lower unit cost per test and higher level of utilization. Although the laser flash technique is much faster than static methods, a single sample test over a moderate temperature range could still take a whole day in traditional systems. Concurrent testing of multiple samples was made available on this system. The graphite and aluminum furnaces are both equipped with six-sample carousels. They provide an opportunity to study five or six specimens concurrently under completely identical conditions.

The purpose of this paper is to summarize the system capabilities and report results for tests on standard reference specimens. Armco iron, stainless steel and AXM-5Q graphite were tested and compared with data in the literature. The tests showed excellent results over the entire temperature range.

\section{Laser Flash Thermal Diffusivity System}

\section{Ultra High Temperature Subsystem}

A schematic of the system is shown in Fig.1. The ultra-high temperature graphite furnace is designed to operate from $500^{\circ} \mathrm{C}$ to $2500^{\circ} \mathrm{C}$ in inert gas environment and up to $2000^{\circ} \mathrm{C}$ in vacuum. It employs a water cooled stainless steel outer shell, molded fibrous carbon insulation, and pyrolitic graphite reflector inside. The graphite heating element is free standing with both power connectors on the bottom. The sample support structure, also of graphite, is an integral part of the furnace. A precision slide mechanism allows the sample holder to be lifted out, co- 


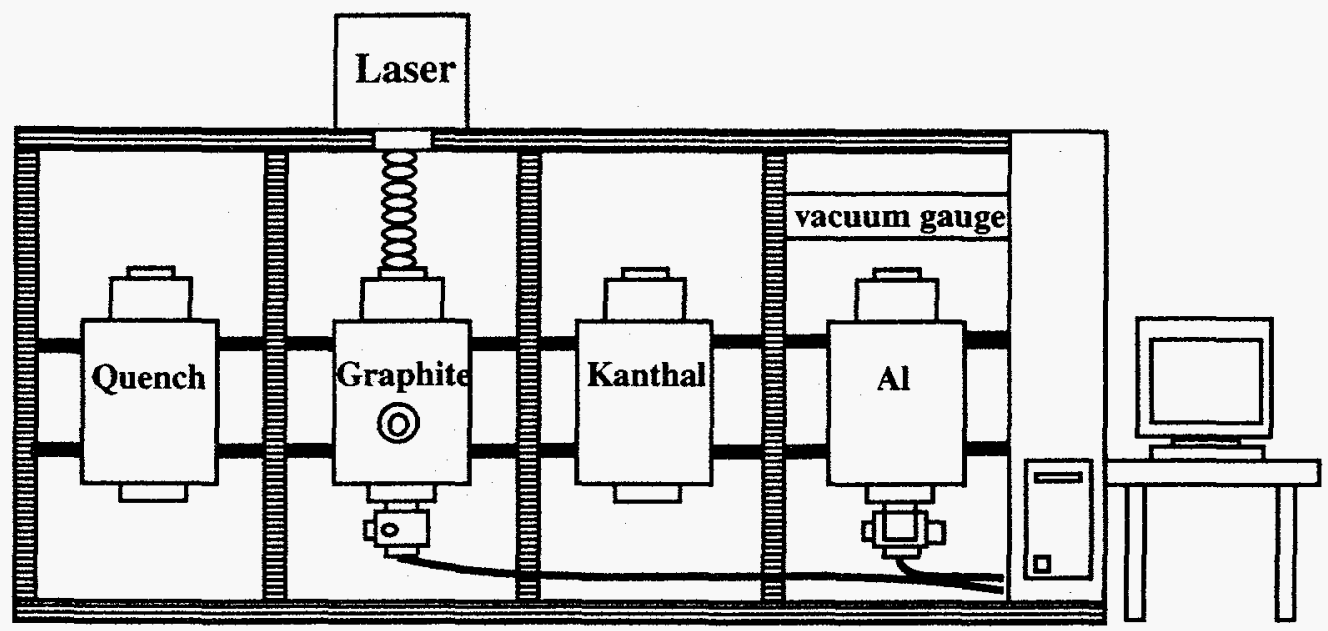

Figure 1. The thermal diffusivity testing system.

linearly with the optical axis. Proper closure is ensured with a sliding seal that engages without a jolt to the sample. A graphite multi-sample carousel allows up to six samples to be loaded and tested during one run. The sample holder is located in the uniform temperature zone of the furnace, and the temperature of the sample holder is monitored by a one-color optical pyrometer.

\section{High Temperature Subsystem}

The high temperature Kanthal Super ${ }^{\mathrm{TM}}$ furnace is designed to operate between room temperature and $1700^{\circ} \mathrm{C}$. The furnace cavity has a 4 inch long hot zone ensuring excellent uniformity and stability in the sample region. The high purity alumina muffle and sample support components allow operation in high vacuum, $\left(10^{-6}\right.$ torr), oxidizing and reducing atmospheres. The alumina muffle also prevents the Kanthal elements from direct exposure to the operating gas. The shell is aircooled and is no more than warm to the touch at maximum operating temperature. Temperature control and sensing is via Type $S$ thermocouples, one close to the heaters and another adjacent to the sample. To operate with hydrogen atmosphere, special valves and a built-in hydrogen sensor were incorporated into the gas controls to monitor the muffle and the furnace cavity in case the muffle tube cracks. The alumina sample holder is configured for a single sample. With judicious use of 
opaque shields in the sample holder, the shine-by of the laser beam due to transparency of alumina is kept at an acceptable level.

\section{Moderate Temperature Subsystem}

The operating range of the low temperature aluminum Monoblock ${ }^{\mathrm{TM}}$ furnace is from $-150^{\circ} \mathrm{C}$ to $500^{\circ} \mathrm{C}$. The design allows the furnace to run in high vacuum, $\left(10^{-6}\right.$ torr) and inert gas environment. Measurement below room temperature is made possible by introducing liquid nitrogen to cooling channels within the furnace block. The sample holder is a six-sample carousel for multiple testing. It is made out of aluminum and stainless steel and has similar design to the graphite furnace carousel.

\section{Quench Furnace}

The fourth furnace is a high speed quench furnace. The radiantly heated sample holder structure will be operable between ambient and $1200^{\circ} \mathrm{C}$. Cooling is provided by a blast of helium once the heat source is turned off. Through various timed and tracked signals, the lower quenched temperature can be programmed. The furnace is designed to measure the thermal diffusivity of a sample at a certain high temperature and then quench the sample at about $200^{\circ} \mathrm{C}$ per second to a secondary temperature to test it again without first having to go ambient. This furnace will be installed and tested during the first quarter of 1996.

\section{Optical Subsystems}

Laser Unit: The laser unit has a Nd:Glass laser with pulse energy up to 35 Joule. The laser head can be moved along a rigid rail above each of the four furnaces. The front face of the laser is equipped with a full complement of key-locked manual controls for diagnostic testing. An interlocked flexible shield connects the laser and the furnace. Full locking is checked by actuated safety switches before firing may occur. Once the beam paths are shielded and interlocked, Class 1 operation is ensured and thus there is no need for safety goggles in the vicinity. The laser power can be varied by changing either the charging voltage (1200 to $2800 \mathrm{~V})$ or the number of high voltage capacitors in parallel connection (1 to 5). The pulse-width may be adjusted by varying the number of parallel capacitors. In addition, the pulsewidth may be stretched by the addition of inductors in the discharge circuit. Several optical components were used to aid the alignment of the laser. A helium/neon alignment laser is located on the laser rail in the same housing. It is used for the 
alignment of the primary laser, and during thermal diffusivity tests to confirm the presence of a sample in the sample holder.

Detection System: Two different photovoltaic detectors are incorporated into the system for versatility. They are mounted underneath the furnaces and monitor the temperature change of the rear surface of the specimen. A high temperature silicon photodiode detector with adjacent preamplifier is shared by the graphite and Kanthal furnaces. Its properties are well suited for use with wavelengths common in high temperature testing. A fiber optic link connects the furnace port and the detector, located 6 feet away. A cryogenically cooled InSb detector with built-in preamplifier is designed for the low temperature aluminum furnace.

A secondary detector subsystem is incorporated into the design to determine the exact shape of the laser pulse. The system maps every laser shot to obtain the precise pulse shape and apply the various pulse width corrections.

\section{Other Subsystems}

The vacuum system consists of a mechanical roughing pump and a turbo molecular pump for high vacuum. All the furnaces share the same vacuum system. In practical use, only one furnace at a time is under vacuum.

Purging gas may be directed to an individual furnace during testing. Two-stage bubblers are used for the exhaust of all the furnaces. The bubbler has an oil reservoir located at the bottom of the assembly and a second reservoir located directly above the first. The design has a ball seal and isolation valve to prevent any air from being pulled into the system during vacuum operation or rapid cool down.

The power supply for the system consists of a water cooled step-down transformer controlled by a low noise controller. Current limiting, water flow sensing, etc., are fully implemented.

\section{Samples}

The system is designed to adapt to a variety of samples. Typical samples are disk-shaped or square-shaped, 6 to $12.5 \mathrm{~mm}$ in diameter and 1 to $6 \mathrm{~mm}$ thick. In addition to bulk specimens, powder and molten metal samples can also be tested. Special containment capsules of quartz or sapphire, are used to test materials through the melt. 


\section{OPERATING SOFTWARE AND DATA ANALYSIS}

The operation of the system is fully computer controlled and automatic. The following functions are provided by the application software:

- Sample identification, test parameters and test setup information.

- Choice of filters and their effect in reducing noise.

- Detailed tabulated corrections by the various methods for each test shot at each temperature.

- Rear temperature vs. time plot for each shot as it occurs. Full display of laser pulse shape, and rear surface temperature excursion.

- Tabulated summary of diffusivity averaged over the multiple measurements at each temperature.

The data analysis methods of the laser flash technique have been well documented [2,3]. The first analysis method was developed by Parker, et. al. [1]. Thermal diffusivity, $\alpha$, was calculated from the thickness, $\mathrm{D}$, and half rise time, $\mathrm{t}_{0.5}$, of the rear surface temperature:

$$
\alpha=\mathrm{CD}^{2} / \mathrm{t}_{0.5}
$$

where $\mathrm{C}$ is a dimensionless parameter. In Parker's method, $\mathrm{C}=0.1388$ under adiabatic conditions. Cowan [4] later developed a mathematical model to include radiation heat losses. Temperature changes at $5 \mathrm{t}_{0.5}$ or $10 \mathrm{t}_{0.5}$ are compared with the temperature change at $\mathrm{t}_{0.5}$ to determine the parameter $\mathrm{C}$. Clark and Taylor [5] proposed a new algorithm for analyzing the radiation heat losses from the temperature vs. time plot before the maximum temperature had been reached. Koski [6] and Heckman [7] incorporated a parameter, L, for heat loss from the front to the rear of the sample for each condition of Clark and Taylor as well as Cowan's method.

The system software incorporates all of the data analysis techniques mentioned. One technique can be chosen before the test as a primary one. After the test, thermal diffusivity values obtained from the various methods are given in a table.

Two layer and three layer materials can also be tested in the system. The analysis is based on the technique developed by Lee and Taylor [8]. Specific heat, density, thickness of each layer and thermal diffusivity of the substrate material are 
required for the calculation. The application software can also calculate the contact resistance between two layers with known diffusivity[8].

\section{STANDARD MATERIALS TESTING}

Several standard materials, SRM 8425 graphite, SRM 1462 stainless steel and ARMCO iron, were used to test the performance of the system. All the samples were disks $12.5 \mathrm{~mm}$ in diameter. Thermal diffusivity of each material was measured as a function of temperature and compared with reference values. The tests were repeated three times to check the reproducibility of the system. Thermal diffusivity data of standard materials are available in the TPRC Data Series from Purdue University [9] and NIST Research Material data sheet.

SRM 8425 graphite samples were tested in the aluminum furnace from $100^{\circ} \mathrm{C}$ to $500^{\circ} \mathrm{C}$ and continued in the graphite furnace from $700^{\circ} \mathrm{C}$ up to $1900^{\circ} \mathrm{C}$. Reference data were calculated from the thermal conductivity values provided on the NIST Research Material data sheet, specific heat values existing in the literature [10] and a density for graphite of $1.73 \mathrm{~g} / \mathrm{cm}^{3}$. The testing results of SRM 8425 graphite

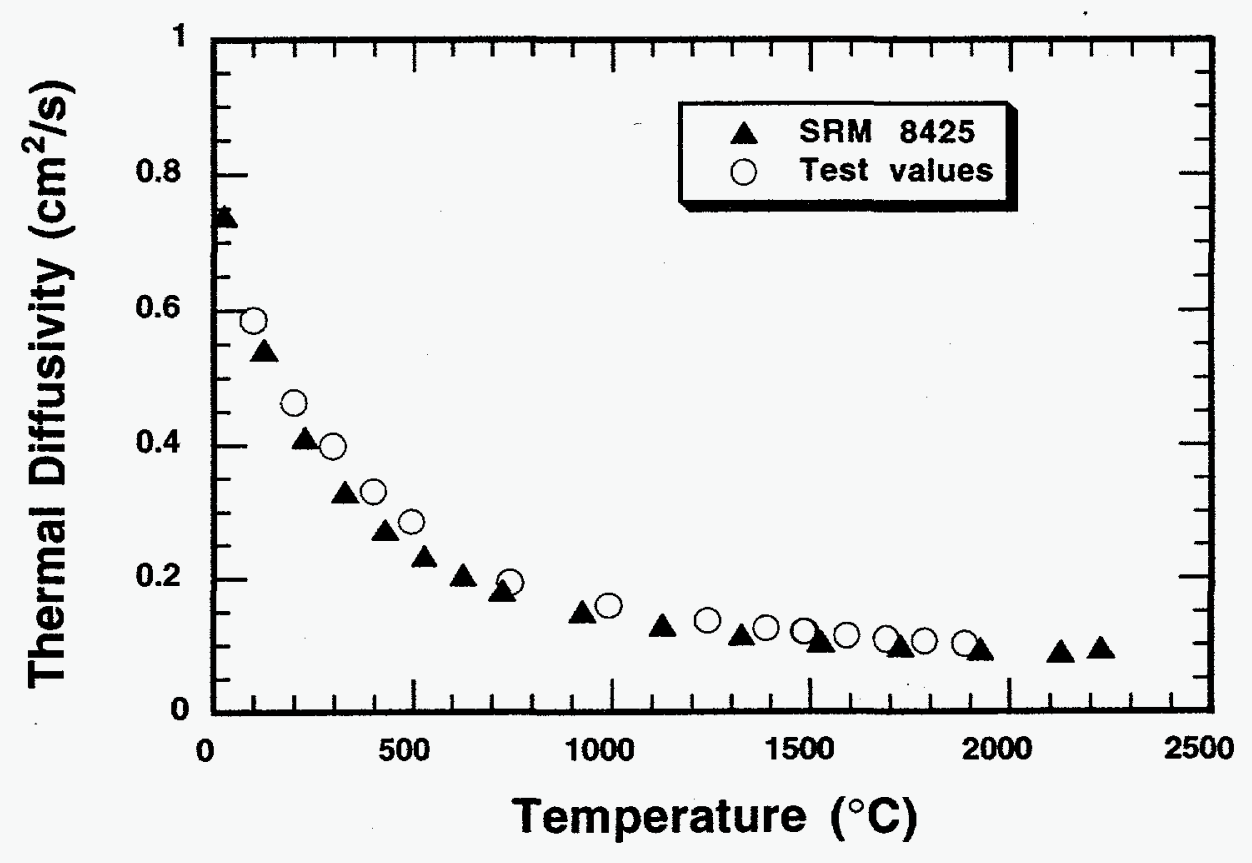

Figure 2. Thermal diffusivity test on SRM 8425 graphite standard sample. 


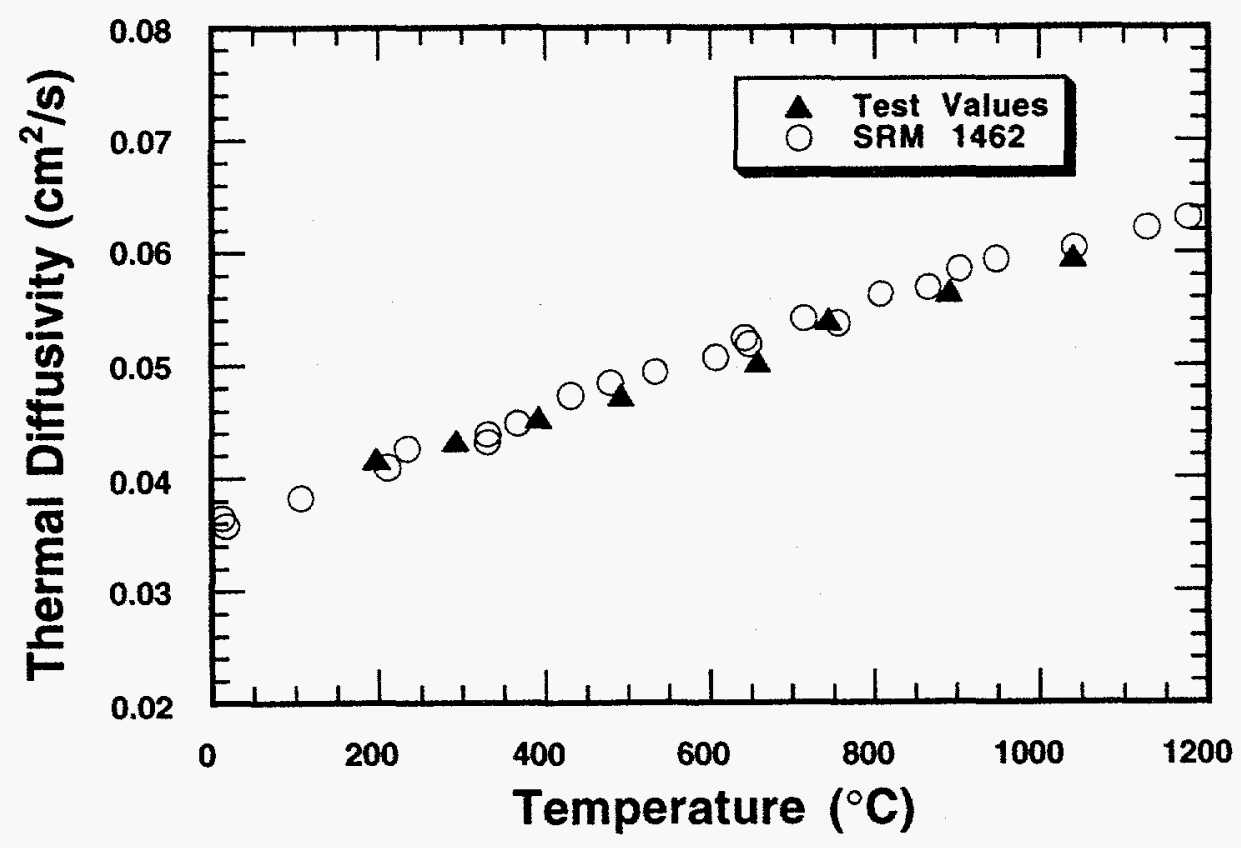

Figure 3. Thermal diffusivity measurement on SRM 1462 stainless steel sample.

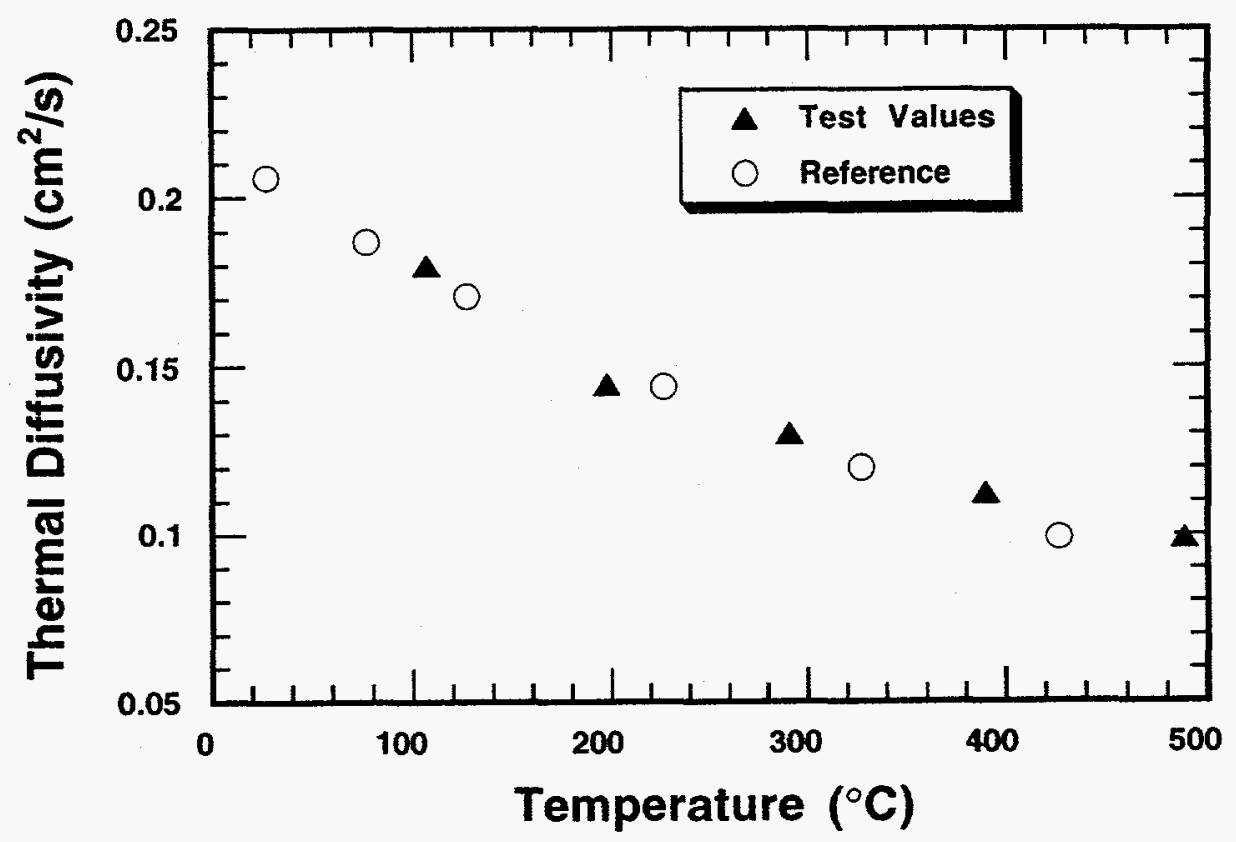

Figure 4. Thermal diffusivity measurement of ARMCO iron standard. 
obtained from the system agreed within $\pm 5 \%$ with the reference curve as shown in Fig. 2. The standard deviation of a single test temperature determined by multiple measurements (multiple laser shots) during each test and among the three repeated tests are within $\pm 3 \%$ of the experimental values shown in Figure 2 .

Stainless steel, SRM 1462 , was tested from $100^{\circ} \mathrm{C}$ to $1050^{\circ} \mathrm{C}$ in both furnaces and compared with reference data $[9,11]$. The results shown in Figure 3 exhibit less than 5\% deviation from the average reference values. An ARMCO iron sample was tested in the low temperature furnace under vacuum condition. The results from 100 to $500^{\circ} \mathrm{C}$ are shown in Figure 4 . They showed very good agreement with Taylor and Clark's data [12] and are within $\pm 5 \%$ of the recommended reference curve [9]. For all the three reference materials, the estimated uncertainties of the reference data values are $\pm 5 \%$ for test temperatures above $300 \mathrm{~K}$.

\section{SUMMARY}

A system has been developed for thermal diffusivity measurements over a wide temperature range and in different environments. The multiple station and concurrent testing concepts have been proven successful for materials characterization. Testing of standard reference materials also showed exceptionally good agreement with literature values; in all cases the experimental values were essentially equal to the reference values. Further tests on layered samples, melts and the quench furnace are planned.

\section{ACKNOWLEDGMENT}

The experimental work was supported by the U.S. Department of Energy, Assistant Secretary for Energy Efficiency and Renewable Energy, Office of Transportation Technologies, as part of the High Temperature Materials Laboratory User Program under contract DE-AC05-960R22464, managed by Lockheed Martin Energy Research Corporation. This research work was also supported in part by an appointment of $\mathrm{H}$. Wang to the ORNL Postdoctoral Research Associates Program administered jointly by ORISE and ORNL. 


\section{REFERENCES:}

[1] Parker, W. J., Jenkins, Butler, C. P. and Abbott, G. L., 1961. "Flash Method of Determining Thermal Diffusivity, Heat Capacity and Thermal Conductivity," Journal of Applied Physics, 32(9): 1679-1684

[2] ASTM Designation E 1461, 1992. "Standard Test Method for Thermal Diffusivity of Solids by the Flash Method," 933-940

[3] Taylor, R.E., 1979. "Heat-Pulse Thermal Diffusivity Measurements," High Temperature - High Pressure, 43(11): 43-58

[4] Cowan, R.D., 1963. "Pulse Method of Measuring Thermal Diffusivity at High Temperatures," Journal of Applied Physics, 34(4): 926-927

[5] Clark, L. M. and Taylor, R. E., 1975. "Radiation Loss in the Flash Method for Thermal Diffusivity," Journal of Applied Physics, 46: 714

[6] Koski, J. A., 1981. "Improved data Reduction Methods for Laser Pulse Diffusivity Determination with the use of Minicomputers," Proceeding of the 8th Symposium of Thermalphysical Properties, Vol. II: 94-103

[7] Heckman, R. C., 1974. "Error Analysis of the Flash Thermal Diffusivity Technique," Thermal Conductivity 14, Klemens, P. G. and Chu, T. K., Eds., Plenum Publishing Co. NY: 491-498

[8] Taylor, R. E., Lee, T. Y. R. and Donaldson, A. B., 1978. "Determination of Thermal physical Properties of Layered Composites by Flash Method," Thermal Conductivity 15, Mirkovich, V. V. ed., Plenum Publishing Co. NY: 135-148

[9] "Thermal Diffusivity," 1973. Thermalphysical Properties of Matter, Purdue University, Vol.10

[10] Deshpande, M. S. and Bogaard, 1983. "Evaluation of Specific Heat Data for Poco Graphite and Carbon-Carbon Composites," Thermal Conductivity 17, Hust, J. G. ed., 17: 45-54

[11] Maglic, K. D., Perrovic, N. and Zivotic, Z., 1980. "Thermal Diffusivity Measurements on Standard Reference Materials," High Temperature-High Pressure, 12: $555-560$

[12] Taylor, R. E. and Clark, L. M., 1974. "Finite Pulse Time Effect in Flash Diffusivity Method," High Temperature - High Pressure, Vol. 2:65-72 